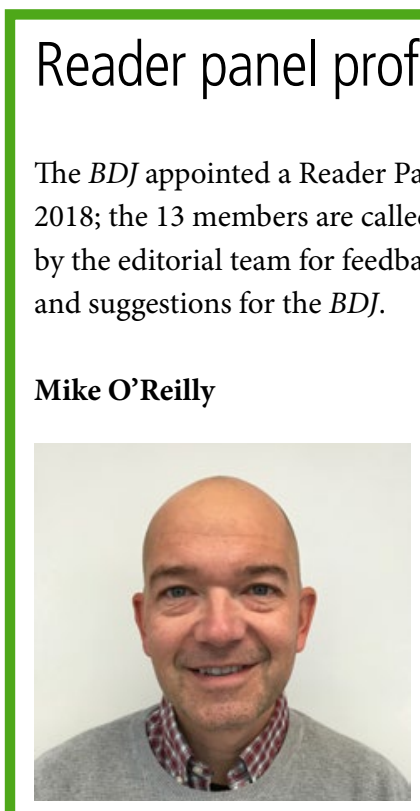

Mike qualified in 1995 from Manchester University and is now a dentist and practice owner in South Cheshire at a mixed practice with two dentists, two dental hygienists and five dental nurses/ receptionists.

Why did you become a dentist? I was interested in science at school and attended work experience at my local dental practice, then subsequently applied to study dentistry at university.

\section{Why did you join the $B D J$ reader panel? I wanted to be involved in shaping the journal from a practice owner/front line dentist point of view so that articles with real relevance to primary care dentists are considered for publication ranging from practice management issues to clinical matters which dentists and their teams can utilise in their daily practice straight away.}

\section{Have you ever changed your practice because of an article you read in the BDJ? A series of articles back in 2013 on minimal intervention dentistry (Minimal Intervention Dentistry; a seven-part series published in 2012 and 2013, Volumes 213 and 214) by Professor Avijit Banerjee [and co-authors] really changed the way I thought about clinical dentistry with regard to the preservation of tooth tissue rather than the drilling and filling dentistry of days gone by. Those articles shaped the way I treat my patients to this day.}

\title{
Dentists strongly advised to read botox advertising guidance
}

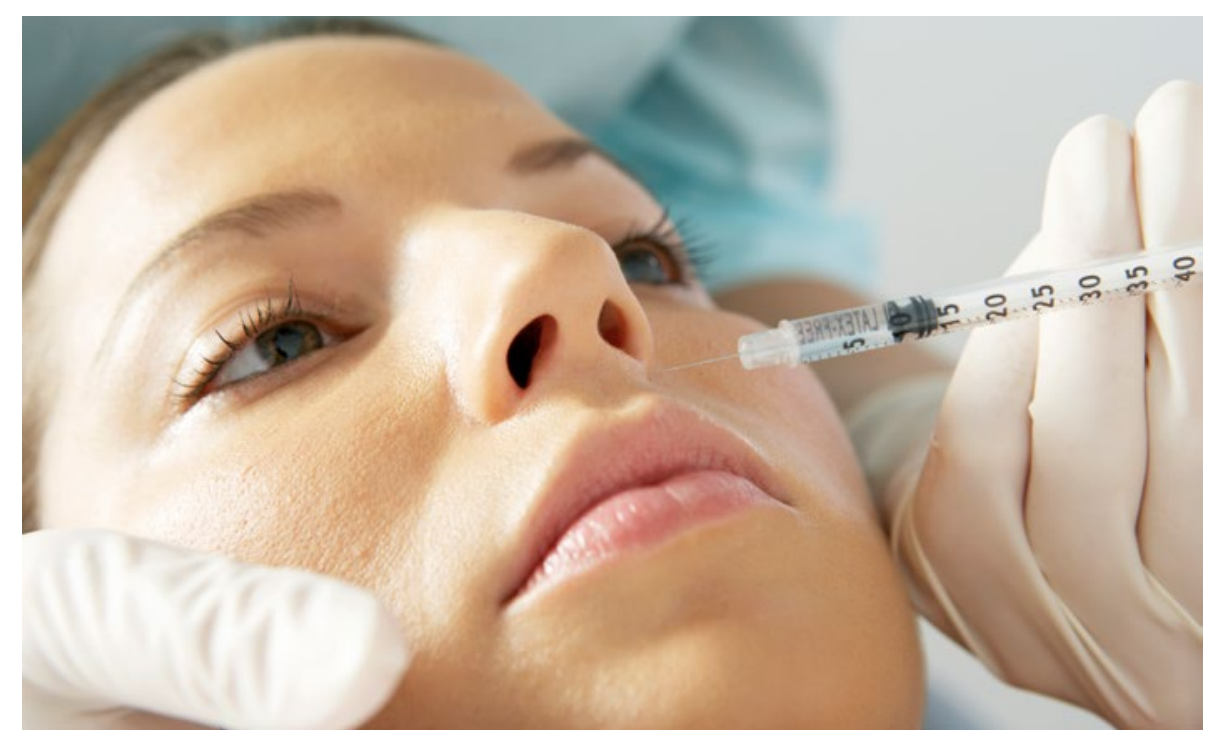

The Faculty of General Dental Practice (FGDP[UK]) is encouraging dentists and dental practices offering botulinum toxin injections to ensure their marketing is legally compliant.

Advertising prescription-only medicines (POMs) to the public breaches the Human Medicines Regulations $2012^{1}$ as well as the Committee of Advertising Practice (CAP) Code, ${ }^{2}$ even when they are to be administered by a registered healthcare professional. The CAP and Advertising Standards Agency have announced that from 1 February 2020 they will use automated technology to identify non-compliant social media posts, which if not removed could result in referral to the Medicines and Healthcare products Regulatory Agency (MHRA) and/or statutory professional regulators such as the General Dental Council (GDC).

To aid compliance, the MHRA and CAP have issued new guidance ${ }^{3}$ which applies to all social media promotion of botox, including paid-for ads, non-paid-for marketing posts and influencer marketing. The guidance says there can be no direct references to a prescription-only medicine or treatment, whether via a brand name, brand-like name or in the generic, including in images and hashtags or in promotions such as sale packages and competition prizes. Indirect references such as 'anti-wrinkle injections' are also banned.
The organisations instead advise promoting professional consultative services, and suggest that advertising 'a consultation for the treatment of lines and wrinkles' may be acceptable. Dermal fillers and other non-POMs are not covered by the enforcement action or guidance, and can still be advertised provided there is no implication that a POM is also available.

Professor Mike Mulcahy, FGDP(UK) Lead on Non-Surgical Facial Aesthetics, said: 'Increasing numbers of dental practices offer injectable cosmetic treatments, and patient demand continues to rise, but many may not be aware of the regulations restricting the advertisement of prescription-only medicines and treatments. To avoid the possibility of facing regulatory action, I strongly advise all dentists who administer botox to read the new guidance and immediately review, and if necessary adapt, their social media, websites and other marketing to ensure compliance.'

\section{References}

1. The Human Medicines Regulations 2012. Available at: http://www.legislation.gov.uk/uksi/2012/1916/contents/ made (accessed 28 January 2020).

2. Advertising Standards Authority. 12 Medicines, medical devices, health-related products and beauty products. CAP Code. Available at: https://www.asa.org.uk/type/ non_broadcast/code_section/12.html (accessed 28 January 2020).

3. Advertising Standards Authority. Enforcement Notice: Advertising Botox and other botulinum toxin injections. 9 January 2020. Available at: https://www.asa.org.uk/ resource/enforcement-notice-botox-social-media.html (accessed 28 January 2020). 